Geopolítica(s) Revista de estudios sobre espacio y poder ISSN: 2172-3958

https://dx.doi.org/10.5209/geop.69249

\title{
Flujos turísticos, geopolítica y COVID-19: cuando los turistas internacionales son vectores de transmisión
}

\author{
Miriam Menchero Sánchez ${ }^{1}$
}

Recibido: 4 de mayo de 2020 / Aceptado: 10 de mayo de 2020

Resumen. El turismo incide en el territorio por medio del movimiento de personas. Las restricciones a los viajes aplicadas para frenar la COVID-19 por casi la totalidad de los países han paralizado prácticamente los flujos internacionales y la actividad turística. Este artículo analiza las medidas realizadas frente a alertas sanitarias previas como la del SARS, MERS o H1N1, y las confronta con las aplicadas ante el nuevo coronavirus. De este modo, se refleja cómo estas últimas pueden alterar el mapa turístico mundial e impactar en los destinos más dependientes, desembocando en un futuro turístico más incierto que nunca.

Palabras clave: pandemia de COVID-19; turismo internacional; flujos turísticos; fronteras; visados.

\section{[en] Tourist Flows, Geopolitics and COVID-19: When International Tourists are Transmission Vectors}

\begin{abstract}
Tourism affects the territory through the movement of people. Travel restrictions applied to curb COVID-19 by almost all countries have practically paralyzed international flows and tourism activity. This article analyzes the measures against the coronavirus and compares them with the measures adopted in the context of the health alerts provoked by SARS, MERS or H1N1. In this way, it is explained that the recent measures can alter the world tourist map and impact the most mobility dependent destinations, leading to a more uncertain tourist future than ever.
\end{abstract}

Keywords: COVID-19 pandemic; international tourism; international flows; borders; visas.

\section{[pt] Fluxos turísticos, geopolítica e COVID-19: quando os turistas internacionais são vetores de transmissão}

Resumo. O turismo afeta o território através do movimento de pessoas. As restrições de viagens aplicadas para parar a COVID-19 por quase todos os países praticamente paralisaram os fluxos internacionais e a atividade turística. Este artigo analisa as medidas tomadas contra alertas sanitários previos, como SARS, MERS ou H1N1, e as compara com aquelas aplicados ao novo coronavírus. Dessa forma, reflete-se como estas últimas podem alterar o mapa turístico mundial e impactar os destinos mais dependentes, levando a um futuro turístico mais incerto do que nunca.

1 Profesora de la Universidad Internacional de La Rioja.

E-mail: miriam.menchero@unir.net 
Palavras-chave: pandemia da COVID-19; turismo internacional; fluxos turísticos; fronteiras; vistos.

Sumario. Introducción. 1. Alertas sanitarias anteriores y turismo internacional. 2. Restricciones al movimiento de viajeros y COVID-19. Reflexiones finales. Referencias.

Cómo citar: Menchero Sánchez, M. (2020). Flujos turísticos, geopolítica y COVID-19: cuando los turistas internacionales son vectores de transmisión. Geopolítica(s). Revista de estudios sobre espacio $y$ poder, 11(Especial), 105-114.

\section{Introducción}

Antes del brote mundial de la COVID-19, el crecimiento turístico esperado para el año 2020 era del 3-4\%, lo que se traducía en un incremento de casi dos millones más de turistas internacionales con respecto al año anterior (OMT, 2020). La paralización de la actividad turística en menos de dos meses ha supuesto pasar de una situación de crecimiento a otra bien distinta de colapso (Vargas, 2020). El turismo supone más del $29 \%$ de las exportaciones mundiales y contribuye al PIB mundial con un 3\%, siendo la tercera actividad económica por detrás de los químicos y los combustibles (OMT, 2019). Su transversalidad supone que la caída del sector tenga un efecto dominó que no sólo afecta al sistema turístico, sino a todos aquellos elementos dependientes directa o indirectamente, incluyendo territorios y economía locales y nacionales.

El coronavirus ha afectado al turismo como ningún otro hecho anterior en la historia (OMT, 2020b), si bien son las consecuencias de las restricciones impuestas a los viajes lo que ha más ha repercutido en el normal desarrollo de la actividad (WTTC, 25 de marzo de 2020). Desde el inicio de la pandemia, los principales organismos internacionales en la materia recomendaban la no reducción de los viajes turísticos por miedo al impacto económico mundial. Sin embargo, las medidas aplicadas son las más severas que se han tomado nunca a nivel mundial, y suponen la inaccesibilidad a multitud de destinos internacionales (OMT, 2020). Según el último informe de la Organización Mundial del Turismo, de primeros de abril, 209 Estados miembros habían adoptado restricciones, lo que representa el $100 \%$ en las regiones turísticas de África, Asia y el Pacífico, el 93\% en Europa y el $92 \%$ en las Américas (2020b).

Cualquier acción que afecte a la movilidad internacional de las personas incide en el turismo, en tanto que esta actividad socioeconómica implica necesariamente el desplazamiento físico. Algo que, genera a su vez una relación entre zonas de origen, tránsito y destino (Navarro et al., 2020). Estos movimientos se definen como flujos turísticos y representan gráficamente las relaciones entre los espacios geográficos (Barrado y Calabuig, 1999). Con un carácter constante, aunque cambiantes y dependientes de los entornos, los flujos internacionales son una muestra de los procesos de globalización e integración mundial. También actúan como discriminatorios entre unas regiones turísticas y otras. De esta manera, Europa, Norteamérica y China constituyen los grandes espacios emisores y receptores. En el aspecto receptivo, también se unen tres cuencas marítimas: el Mediterráneo, el 
Sudeste Asiático y el Caribe. En 2018, los diez principales destinos mundiales, recibieron más del 40\% de las llegadas e ingresos internacionales (OMT, 2019) ${ }^{2}$.

\section{Alertas sanitarias anteriores y turismo internacional}

El proceso de globalización, unido al volumen de viajeros internacionales, ha incidido en una mayor propagación de enfermedades infecciosas, nuevas y reemergentes, que, a modo de brotes de gripe, ébola o zika, entre otros, han aumentado significativamente por todo el escenario internacional. De hecho, el turismo es reconocido por la comunidad médica como un vector para la transmisión de enfermedades y, por ende, se encuentra vinculado con la salud pública y la seguridad turística (Sancho, 1998) ${ }^{3}$. A tal efecto, el aumento del transporte internacional, y concretamente el aéreo, tiene una incidencia clave en la propagación de microorganismos, ya que por este medio los turistas no necesitan más de 36 horas para recorrer el mundo. Esto es, el mismo tiempo que necesita "cualquier patógeno para viajar desde una aldea remota a las principales ciudades de todos los continentes" (Foro Económico Mundial, 2019). El turista, además de portador, también puede contribuir a la aparición de virus desconocidos por medio del contacto y la realización actividades sobre destinos exóticos (Rodríguez-García, 2001).

Más allá de las pérdidas humanas, este tipo de enfermedades suponen un impacto social y económico en los países de origen y de destino. En estos últimos, su importancia recae en la alta interacción de personas en espacios públicos y privados, derivado del contacto entre residentes y turistas y, a su vez, entre turistas de diferencias procedencias (Ruiz et al., 1994). Por ello, los destinos deben tener dotaciones sanitarias y personal médico suficiente para atender este tipo de emergencias, considerando tales elementos como indicadores de su seguridad y competitividad turística. Sin embargo, existe una tendencia a desatender los aspectos sanitarios y/o epidemiológicos en la planificación turística de los destinos, sobre todo, en los menos avanzados (Moura, 2004). Por su parte, en los países de origen, los casos "importados" también suponen un incremento en la estructura sanitaria (personal, medicamente, dispositivos) cuya importancia está marcada por el tipo de brote y con independencia de lo avanzado que esté o no su particular sistema de salud (Joo et al., 2019).

El turismo ha afrontado numerosas crisis epidemiológicas recientemente, como el MERS (2012-2015), el H1N1 (2009) o el SARS (2003), siendo este último el que mayor incidencia ha tenido sobre el turismo internacional hasta la llegada de la COVID-19. Aunque tienen ubicaciones, alcances y duraciones muy diferentes entre sí, todas comparten con el coronavirus su afectación a las regiones y flujos turísticos internacionales. Así, el Síndrome Respiratorio de Oriente Medio (MERS-

2 Por países, los veinte receptores son: Estados Unidos, España, Francia, Tailandia, Reino Unido, Italia, Australia, Alemania, Macao, Japón, Hong Kong, China, India, Turquía, México, Emiratos Árabes Unidos, Austria, Canadá, Singapur y Malasia. Respecto a los emisores: China, Estados Unidos, Alemania, Reino Unido, Francia, Australia, Canadá, Rusia, Corea del Sur, Italia, Hong Kong, Singapur, España, Bélgica, Países Bajos, Brasil, India, Japón, Taiwán, Emiratos Árabes Unidos (OMT, 2019).

3 Según Rodríguez-García (2001) viajar es considerado un factor de salud pública desde la Edad Media Occidental, cuando ciudades como Venecia ya imponían cuarentenas a los pasajeros de barcos para protegerse de posibles enfermedades infecciosas. 
CoV) se originó en la península arábiga en torno al año 2012, y se mantuvo activo hasta el 2014, con casos importados a Europa, África, Norteamérica y AsiaPacífico, confirmándose que los flujos turísticos habían sido una vía de transmisión. No obstante, la OMS no sugirió ninguna restricción a los viajes y sólo recomendó pautas de higiene y seguridad alimentaria, si bien Arabia Saudí sí limitó la asistencia de peregrinos internacionales a eventos religiosos (Pavli et al., 2014). El MERS tendría un nuevo brote en Corea del Sur, en el año 2015, ocasionando 38 muertes y dejando a 16.000 personas en cuarentena. Las llegadas internacionales se redujeron en el país en un 16\% y se perdieron 2.600 millones de dólares en el sector, aunque el efecto sobre el PIB fue pequeño, dado que el turismo sólo aportaba el 5,1\% (Joo et al., 2019). Aunque la OMS tampoco recomendó restricciones, países cercanos como Taiwán, Hong Kong y China emitieron sus propios avisos de viaje, y Corea del Sur, por su parte, recomendó la no afluencia a espacios ni lugares concurridos.

Por el contrario, el virus influenza AH1N1, mal llamado "gripe porcina", sí tuvo consecuencias negativas para el turismo mexicano. Desde su brote en el año 2009, se han detectado más de 900 casos mortales, especialmente en México, Estados Unidos y Canadá, aunque también en Europa. La OMS ha llegado a señalar casi 30.000 casos detectados hasta la actualidad, por lo que llegó a clasificar al virus como "pandémico". En un primer momento, México cerró centros educativos, de ocio y recreación, y se recomendó el distanciamiento social, así como el lavado de manos, el uso de mascarillas y la vigilancia médica en terminales de transporte. En Estados Unidos, los grupos más conservadores solicitaron cerrar la frontera común y Francia llegó a interrumpir el tráfico aéreo, alentando a que toda Europa hiciera lo mismo. Con esta situación, la región más afectada fue Yucatán, y especialmente los destinos internacionales de Cancún y Riviera Maya, en donde la ocupación bajó al $25-30 \%$ frente al $65-70 \%$ que era habitual. La pérdida económica del sector se ha cifrado en unos cinco mil millones de dólares (Oehmichen-Bazán y París, 2010).

Finalmente, el Síndrome Respiratorio Agudo Grave (SARS) se originó en China continental, en el año 2003. En pocos meses, la enfermedad se había propagado en más de doce países de Norteamérica, Latinoamérica, Europa y Asia, afectando a más de 8.000 personas, de las cuáles, al menos, 750 fallecieron (McKercher, 2004). En término globales, el SARS supuso un descenso del turismo mundial cifrado en torno a un $-0,4 \%$ respecto al año 2002 , y que se traduce en tres millones de turistas internacionales menos (OMT, s.f.). El sector perdió entre treinta y cincuenta mil millones dólares e incluso afectó a países que estaban libres de la enfermedad (WTTC, 24 de enero de 2020). Ante los resultados, la OMS realizó por primera vez en 45 años el primer "aviso de viaje" por enfermedad infecciosas, lo que originó una reacción en cadena. China, Hong Kong, Malasia y la ciudad de Toronto cerraron sus fronteras; Tailandia obligó a que los turistas portaran mascarillas y se impusieron cuarentenas a pasajeros con síntomas. Más de 110 países aplicaron algún tipo de restricción a los turistas chinos continentales.

Estos y otros brotes de menor repercusión han impulsado la aceleración de una mayor coordinación internacional entre salud y turismo, especialmente en la mejora de protocolos, la toma de decisiones, la comunicación y las medidas relativas a los viajes internacionales (OMT, s.f.). Al respecto, la OMS (2009) ha reconocido que prefiere "pecar por exceso de precaución", debido al desconocimiento y la gravedad que conlleva cualquier brote u oleada internacional. Sin embargo, la ré- 
plica de esta posición ha llevado a una reacción secuencial reactiva y expansiva por parte de los gobiernos. Según McKercher (2004), las reacciones institucionales por amenazas más percibidas que reales son las que pueden conducir a los colapsos turísticos, ya que pueden modificar los flujos turísticos internacionales si existen medidas o decisiones exageradas o una falta de coordinación ante la crisis sanitaria.

Así, con la declaración de la "emergencia sanitaria de preocupación internacional" (PHEIC) el 31 de enero de 2020, la OMS junto a la OMT no recomendaban aplicar restricciones de viaje, y señalaban que cualquier medida respecto al turismo debía ser proporcional a la amenaza real para la salud pública (OMT, 2020). Entre las medidas no adecuadas se señalaba el cierre de fronteras o la prohibición a viajar, y por el contrario, se instaba a iniciativas como la activación de protocolos de salud pública en los puntos de entrada internacionales o el reconocimiento médico de viajeros sospechosos. Sin embargo, estas dos últimas acciones son recogidas en el Reglamento Sanitario Internacional (RSI), cuyo artículo 43 permite que a partir de ellas se pueda denegar la entrada o salida de viajeros internacionales -lo que interfiere per se, el tráfico turístico internacional.

\section{Restricciones al movimiento de viajeros y COVID-19}

Por todo lo anterior, aun cuando al principio del brote de coronavirus las dos principales medidas adoptadas fueron las restricciones de viajeros procedentes de países afectados y la invalidación de visados, éstas ya afectaban de por sí, y en gran medida, a los flujos turísticos internacionales. Cuando la OMS declaró al coronavirus como "pandemia", el 11 de marzo, los países comenzaron, de manera masiva, a utilizar medidas más extremas de contención, tales como el cierre de fronteras y la suspensión del tráfico aéreo internacional a gran escala; dos categorías que no habían estado en uso antes de la COVID-19. Las cifras del último informe de la OMT constatan este cambio de dinámica (Tabla 1).

Tabla 1. Incremento de restricciones por regiones turísticas (febrero-abril 2020)

\begin{tabular}{|l|r|r|r|r|r|r|r|r|r|}
\hline \multirow{2}{*}{ Regiones } & \multicolumn{2}{|c|}{$5-10$ febrero } & \multicolumn{2}{c|}{$9-16$ marzo } & \multicolumn{2}{c|}{$16-24$ marzo } & $24-6$ abril & Global \\
\cline { 2 - 11 } & $\begin{array}{c}\text { Núm. } \\
\text { países }\end{array}$ & $\begin{array}{c}\% \\
\text { Incr. }\end{array}$ & $\begin{array}{c}\text { Núm. } \\
\text { países }\end{array}$ & $\begin{array}{c}\% \\
\text { Incr. }\end{array}$ & $\begin{array}{c}\text { Núm. } \\
\text { países }\end{array}$ & $\begin{array}{c}\% \\
\text { Incr. }\end{array}$ & $\begin{array}{c}\text { Núm. } \\
\text { países }\end{array}$ & $\begin{array}{c}\% \\
\text { Incr. }\end{array}$ & $\begin{array}{c}\% \\
\text { Incr. }\end{array}$ \\
\hline Asia y Pacifico & 31 & $60 \%$ & 36 & $44 \%$ & 42 & $23 \%$ & 46 & $22 \%$ & $100 \%$ \\
\hline Américas & 9 & $17 \%$ & 15 & $19 \%$ & 37 & $20 \%$ & 47 & $22 \%$ & $92 \%$ \\
\hline Europa & 7 & $13 \%$ & 12 & $15 \%$ & 48 & $27 \%$ & 50 & $24 \%$ & $93 \%$ \\
\hline Oriente Medio & 3 & $6 \%$ & 9 & $11 \%$ & 12 & $7 \%$ & 13 & $6 \%$ & $100 \%$ \\
\hline África & 2 & $4 \%$ & 9 & $11 \%$ & 42 & $23 \%$ & 53 & $25 \%$ & $100 \%$ \\
\hline Mundo & 52 & $100 \%$ & 81 & $100 \%$ & 181 & $100 \%$ & 209 & $100 \%$ & $96 \%$ \\
\hline
\end{tabular}

Fuente: Elaboración propia a partir de OMT (2020).

Si bien con anterioridad a la declaración de pandemia, sólo 52 países habían impuesto algún tipo de medida, principalmente Asia y Pacífico, a partir de esta fecha, el número se incrementa por encima de los 200, afectando de manera global y sostenido a todas las regiones turísticas. Este aumento es especialmente significativo en el periodo comprendido entre el 9 y el 24 de marzo. También son reseña- 
bles los experimentados en Europa y África, especialmente en los dos últimos periodos. Así pues, este informe, elaborado a principios de abril, cuando aún no se preveía un final para la pandemia, ya señalaba una restricción sobre los viajes mundiales equivalente al 96\%. De hecho, y según el propio organismo, no se conoce aún el impacto sobre el turismo que puede llevar apareado este escenario global.

Las fronteras son consideradas como uno de los elementos más eficientes para el control del flujo de personas (Timothy, 2001) y también un lugar estratégico para evitar la transmisión de enfermedades infecciones (García-Rodríguez, 2001). Por ello, el cierre de éstas ha sido una de las medidas más contundentes y utilizadas por parte de los países frente a la COVID-19 (Yang et al., 2020), aunque su aplicación limita la tendencia internacional hacia la facilitación del movimiento internacional de personas, plasmada en numerosos acuerdos multilaterales y bilaterales como el espacio Schengen (1995). Estas alianzas han beneficiado indirectamente al turismo, no sólo por el libre flujo de viajeros, sino también por la simplificación de procesos y visados, así como por los acuerdos con medios de transportes, especialmente aéreos (Timothy, 2026).

Empero, a principio de abril, 90 países habían cerrado completamente sus fronteras, incluyendo todo el espacio Schengen. De entre todos, siete se encuentran entre los 20 países receptores de turismo mundial, como es el caso Austria $\left(17^{\circ}\right)$, Canadá $\left(18^{\circ}\right)$, China $\left(12^{\circ}\right)$, Singapur $\left(19^{\circ}\right)$ o Malasia $\left(20^{\circ}\right)$, destacando España $\left(2^{\circ}\right)$ y Australia $\left(10^{\circ}\right)$. Otros 44 países han implementado cierres de fronteras condicionados, esto es, limitando el ingreso en función de la procedencia (OMT, 2020,6). Grandes receptores turísticos como Estados Unidos $\left(1^{\circ}\right)$, Francia $\left(3^{\circ}\right)$ y Alemania $(8)^{\mathrm{o}}$ estarían aplicando este tipo de medidas, junto a otros importantes destinos internacionales como Turquía $\left(14^{\circ}\right)$, Japón $\left(10^{\circ}\right)$ o Hong Kong $\left(11^{\circ}\right)$.

Según Timothy (2006), los aeropuertos son fronteras de importancia vital para el turismo, pues la conectividad aérea supone más de la mitad de los viajes a nivel mundial y son los principales puntos de entrada de viajeros en los destinos insulares internacionales (OMT, 2020). La suspensión del tráfico aéreo es una medida muy vinculada, por tanto, al cierre de frontera, y ha sido aplicada por hasta 56 países $\left(27 \%\right.$ del total). De ellos, Tailandia $\left(4^{\circ}\right)$, Italia $\left(6^{\circ}\right)$ y Macao $\left(9^{\circ}\right)$ forman parte de los principales destinos receptores mundiales, aunque también han establecido estas acciones Estados Unidos $\left(1^{\circ}\right)$, India $\left(13^{\circ}\right)$ y Emiratos Árabes Unidos $\left(16^{\circ}\right)$. Atendiendo a estos datos, el Consejo Internacional de Aeropuertos (ACI) y la Asociación Internacional de Transporte Aéreo (IATA) han estimado que el impacto del coronavirus puede suponer que el tráfico internacional de pasajeros disminuya hasta un $40 \%$ a nivel mundial (Ramón, 2020).

Los visados están adquiriendo una nueva importancia, si bien, este trámite siempre ha contado con una gran influencia en el turismo internacional, dado que no sólo suponen seguridad y control de la demanda, sino que también comportan ingresos por la aplicación de tasas turísticas (Rifai, 2014). Pueden llegar a ser un factor disuasorio para la demanda en función de la complejidad, el costo y duración para su obtención. De hecho, el "índice de apertura" mide la simplificación y eliminación de los visados temporales y/o de turistas. Así, mientras que hace 40 años, el $75 \%$ de la población necesitaba un visado para poder viajar, el año pasado se había reducido hasta el 53\%, siendo Europa, Latinoamérica, Asia Meridional y África Oriental las regiones con mayores políticas de exención (OMT, 2019). 
Ante el brote de coronavirus, seis países han vuelto a imponer visados, como es el caso de Bangladesh, Bután, Irán, Laos, Malawi y Myanmar, lo que puede condicionar la conformación de ciertos flujos, así como su comercialización turística. Aunque se trata de una restricción menor, conviene analizar su evolución y evitar cualquier vuelta a la burocratización, especialmente ante la posibilidad de establecer algún tipo de certificado médico obligatorio ${ }^{4}$.

Finalmente, la OMT (2020b) ha llegado a analizar otro tipo de medidas como el establecimiento de cuarentenas o confinamientos, de aproximadamente, unos 14 días. Países turísticos como Barbados, Irlanda, Italia y Tanzania, entre otros, han aplicado estas restricciones que impiden el desarrollo normal de un viaje turístico, no sólo por el sobrecoste que implican, sino también por la imposibilidad de visitar y realizar actividades turísticas en el destino.

Más allá de las actuales restricciones físicas que se están imponiendo a nivel global, se están realizando análisis que inciden en las barreras psicológicas de los turistas, e incluso de los propios gobiernos. Como señala el Consejo Mundial de los Viajes y el Turismo (WTTC, 24 de enero de 2020), las medidas de gestión de la crisis también deben incluir un manejo del miedo y de la influencia de éste en las decisiones y comportamientos presentes y futuros de los turistas internacionales. La percepción de riesgo y contagio puede actúan nuevamente tanto en las regiones emisoras como receptoras, y puede tener como afectar directamente al turista. El miedo puede ser un motivo para decidir no viajar a un determinado lugar y paralizar su demanda turística, pero también puede ser un proceso político para seleccionar qué turistas pueden visitar una región turística.

Además, la estigmatización de viajeros procedentes de países puede desembocar en un conflicto social sobre el propio destino. Esto último ha sido un aspecto recurrente en las tres pandemias referidas, especialmente respecto a los turistas mexicanos y chinos (Oehmichen-Bazán y París, 2010). Según la WTTC, en febrero y antes de la propagación mundial, ya se señalaba a los turistas chinos. Más allá de la implicación social de estas prácticas, este mercado chino es el mayor emisor turístico del mundo, con un 16\% del gasto internacional, por lo que dicha discriminación también puede implicar un efecto económico sobre el sector. De hecho, la percepción de amenaza o riesgo de nuevos rebrotes y los mensajes y medidas que se propaguen desde los entes nacionales e internacionales serán fundamentales para la estabilidad turística. Así sucedió con el SARS, cuyas repetidas alertas por parte de organismos de salud fueron el principal motivo para que el turismo casi se erradicara en Asia (McKercher, 2004).

\section{Reflexiones finales}

Casi un mes después de la última actualización de la OMT ningún país ha tomado medidas para el levantamiento de las restricciones a los viajes internacionales. Las organizaciones internacionales turísticas están siendo muy críticas con la gestión

4 El auge del "pasaporte sanitario" en un escenario pandémico como el actual, no sólo requiere de la disponibilidad de pruebas para toda la población, sino de la consideración de que estas sean legales en función de la procedencia y destino del viajero. La no regulación y accesibilidad de tests podrían incidir en la democratización de la actividad turística. 
del coronavirus, señalando que muchas de las acciones tomadas por los gobiernos tienen un mayor impacto en el sector que el brote en sí mismo (WTTC, 24 de enero de 2020).

El turismo tiene un historial de crisis económicas y sanitarias que verifica su propia resiliencia. Prueba de ello es que el tiempo promedio de recuperación ha disminuido de 26 a 19 meses, entre 2001 y 2018 , y se considera que podría incluso reducirse a 10 meses (WTTC, 11 de febrero de 2020). Esto se corresponde con los peores pronósticos de los expertos, que sitúan la reanudación del sector turístico en el próximo año, si bien también existen voces que sitúan escenarios más favorables, con indicios hacia el mes de mayo, o entre julio y septiembre (Navarro et al., 2020). No obstante, todos coinciden en señalar un proceso flexible y progresivo, que irá desde una escala local hasta otra global. El regreso a la normalidad, de ser factible, debe incluir necesariamente el levantamiento de las actuales medidas impuestas a la movilidad de personas.

Como se ha mostrado, la comunicación y las decisiones políticas en la materia, incluyendo la de los organismos sanitarios y turísticos, resultan vitales, ya que pueden conllevar el aumento o no de aspectos como la incertidumbre, el miedo e incluso la discriminación. La importancia de los casos importados y las declaraciones de zonas de riesgo inciden en ello. También, el intercambio de información entre destinos, la coordinación correcta entre el sector público y privado y la imposición de políticas inadecuadas de control de personas. Asimismo, lo concerniente a la burocratización de los visados o el aumento de su coste (WTTC, 11 de febrero de 2020). Todas estas medidas, que incluyen el cierre del espacio aéreo internacional, inciden en los flujos internacionales turísticos, pudiendo modificarlos o paralizarlos. Esta situación podría ser preocupante para aquellos destinos cuyas económicas son altamente dependientes del turismo, pero como se señalaba al comienzo, también para las exportaciones internacionales.

Según la Organización de las Naciones Unidas, las llegadas internacionales turísticas pueden reducirse entre un 20 y un 30\% (OMT, s.f.). Otras estimaciones ya sitúan a Asia y Pacífico como la región más afectada, con hasta 49 millones de empleos en riesgo y una pérdida estimada de 800 mil millones de dólares. A ella le seguirían Europa, con hasta diez millones de empleos y 552 mil millones dólares, y Norteamérica, con 7 millones de empleos y 570 mil millones de dólares. Unas cifras que demuestran una evidente relación con los flujos internacionales predominantes. De igual manera, destinos importantes como Brasil, Reino Unido, Italia, Alemania, Francia, Japón, Indonesia e India serían alguno de los más afectados (WTTC, 25 de marzo de 2020).

El impacto de la COVID-19 en el turismo mundial comienza a acaparar más tiempo en los medios divulgativos y de comunicación, a medida que la pandemia comienza a remitir, pero también permite vislumbrar sus alcances. Los indicadores turísticos son de especial preocupación por sus resultados negativos y por la repercusión de estos. A ello se suma la crítica por parte de la comunidad turística respecto a que ha existido una "demora colectiva (...) para reaccionar lo suficientemente rápido como para ayudar a un sector que es la columna vertebral de la economía global" (WTTC, 25 de marzo de 2020). Un sector globalizado que actualmente es dependiente de las medidas políticas proteccionistas que imponen tanto los espacios emisores como los receptores. Sin embargo, más allá de esto, el sector turístico es un ámbito transversal en donde los turistas internacionales, con su sólo movi- 
miento, pueden alterar muchas de las dinámicas geopolíticas, sanitarias y psicosociales de la sociedad global actual.

\section{Referencias}

Barrado, D., y Calabuig, J. (1999). Geografía mundial del turismo. Madrid: Síntesis.

Foro Económico Mundial. (2019). Informe sobre competitividad en viajes y turismo. Ginebra: Foro Económico Mundial.

Joo, H. et al. (2019). Economic Impact of the 2015 MERS outbreak on the Republic of Korea's tourism - related industries. Health Security, 17(2), 100-108.

McKercher, B. (2004). The Over-reaction to SARS and the Collapse of Asian Tourism. Annals of Tourism Research, 31(3), 716-719.

Mesplier, A., y Bloc-Duraffour, P. (2000). Geografia del turismo en el mundo. Madrid: Síntesis.

Moura, G. (2004). O impacto económico do dengue no turismo. Revista Turismo em Análise, 15(1), 13-211.

Navarro, E. et al. (2020). Propuesta de reflexión desde el turismo frente al COVID-19: Incertidumbre, impacto y recuperación. Málaga: Instituto Universitario de Investigación de Inteligencia e Innovación Turística.

Oehmichen-Bazán, C., y París, M. D. (2010). El miedo ante el riesgo global: apuntes sobre la emergencia del virus A/H1N1 y el turismo. Nuevas tendencias en Antropología, (1), 161-185.

OMT. (2019). Panorama del turismo internacional (Edición 2019). Madrid: Organización Mundial del Turismo.

OMT. (2020). Turismo y COVID-19 (actualización 13 de marzo de 2020). Madrid: Organización Mundial del Turismo.

OMT. (2020b). COVID - 19: related travel restrictions, a global review for tourism (first report as of 16 april 2020). Madrid: Organización Mundial del Turismo.

OMT. (s.f.). Evaluación del impacto del brote de covid-19 en el turismo internacional. Madrid: Organización Mundial del Turismo.

Pavli, A. et al. (2014). Middle East respiratory síndrome coronavirus (MERS - CoV): Prevention in travelers. Travel Med Infect Disease, 12(6), 602-608.

Ramón, D. (2020). Hoja de ruta para reactivar los aeropuertos tras la COVID - 19. Hosteltur, 20 de abril.

Rifai, T. (2014). Turismo internacional y agilización de visados. Estudios Turísticos, (200), 9-18.

Rodríguez-García, R. (2001). The Health - development link: travel as a public Health issue. Journal of Community Health, 26(2), 93-112.

Ruiz, M. et al. (1994). Salud y turismo. Salud Pública de México, 36(1), 61-69.

Sancho, A. (1998). Introducción al turismo. Madrid: Organización Mundial del Turismo.

Timothy, J. (2001). Tourism and Political Boundaries. Londres: Routledge.

Timothy, J. (2006). Relationships between Tourism and International Boundaries. En H. Wachowiak (Ed.), Tourism and Borders: Contemporary Issues, Policies and International Research (pp.9-18). Aldershot: Ashgate.

Vargas, A. (2020). El turismo postcoronavirus (III). Hosteltur, 25 de marzo. 
WTTC. World Travel \& Tourism Council. (2020). Chinese and Asian tourists must not be stigmatised because of coronavirus, says. WTTC, 11 de febrero.

WTTC. World Travel \& Tourism Council. (2020). Containing the spread of panic is as important as stopping the coronavirus itsefl, says. WTTC, 24 de enero.

WTTC. World Travel \& Tourism Council. (2020). Latest research from WTTC shows a $50 \%$ increase in Jobs at risk in Travel \& Tourism. WTTC, 25 de marzo.

Yang, Y. et al. (2020). Coronavirus pandemic and tourism: Dynamic stochastic general equilibrium modeling of intectious disease outbreak. Annals of Tourism Research. En prensa. 